\title{
Modulation of the expression of sirtuins and vargenes by heat shock in the malaria parasite Plasmodium falciparum. a pattern emerges
}

\author{
Linda 0. Anagu ( $\sim$ lo.anagu@unizik.edu.ng) \\ Department of Pharm. Micro. and Biotech., Nnamdi Azikiwe University, Anambra, 5021, Nigeria \\ https://orcid.org/0000-0002-2243-1616
}

\section{David R. Hulse}

School of Life Sciences, Keele University, Staffordshire, ST5 5BG, UK

Paul D. Horrocks

School of Medicine, Keele University, Staffordshire, ST5 5BG, UK

Srabasti J Chakravorty

School of Life Sciences, Keele University, Staffordshire, ST5 5BG, UK

\section{Research Article}

Keywords: Plasmodium, var, antigenic variation, sirtuin, Sir2A, Sir2B, heat shock

Posted Date: April 6th, 2021

DOI: https://doi.org/10.21203/rs.3.rs-396479/v1

License: (1) This work is licensed under a Creative Commons Attribution 4.0 International License. Read Full License 


\section{Abstract}

Background: In the malaria parasite Plasmodium falciparum the expression of ' $v a r^{\prime}$ ' virulence genes is regulated through epigenetic mechanisms. Its sirtuin epigenetic regulators have a direct effect on vargene expression patterns, are increased in a laboratory strain of $P$. falciparum exposed to heat shock and are positively associated with fever. A Gambia study extended this association to blood lactate and vargenes commonly expressed in severe malaria, and between PfSir2A and group B var. A Kenyan study extended this association to between PfSir2A and overall vartranscript level. These observations suggest a mechanism through which stress phenotypes in the human host might be sensed via a parasite sirtuin, and virulence gene expression modulated accordingly.

Methods: In vitro experiments were conducted using laboratory and recently-laboratory-adapted Kenyan isolates of $P$. falciparum to follow up the correlative findings of the field study. To investigate a potential causeand-effect relationship between host stress factors and parasite gene expression, qPCR was used to measure the expression of sirtuins and var genes after highly synchronous cultured parasites had been exposed to $2 \mathrm{~h}$ or $6 \mathrm{~h}$ of heat shock at $40^{\circ} \mathrm{C}$ or elevated lactate.

Results: Heat shock was shown to influence the expression of PfSir2B in the trophozoites, whereas exposure to lactate was not. After the ring stages were exposed to heat shock, sirtuins, severe-disease-associated ups $A$ and upsB vargenes and vargenes in general were not altered. More biological replicate experiments will be needed to confirm our observations.

Conclusions: This study demonstrates that heat stress in laboratory and recently-laboratory-adapted isolates of $P$. falciparum results in a small increase in PfSir $2 B$ transcripts in the trophozoite stages only. We could not establish if heat shock can cause an increased expression of sirtuins or vargenes in the ring stages. By contrast, the association between hyperlactataemia and sirtuin/vargene expression that was previously observed in vivo appears to be coincidental rather than causative.

\section{Background}

Several hundred thousand people die from malaria each year: in 2018, 405,000 deaths were recorded. This is almost always due to infection with the malaria parasite species $P$. falciparum, which can cause severe and lethal malaria, and children make up $67 \%$ of this mortality [1]. Severe malaria manifests as three major syndromes: cerebral malaria, acute respiratory distress due to metabolic acidosis and severe anaemia (mainly in young children) [2]. Severe malaria is defined by a group of clinical factors including fever of above $39^{\circ} \mathrm{C}[3$, $4]$ and high blood lactate of $\geq 5 \mathrm{mM}[1,3,5,6]$. Fevers usually last between 2 and $6 \mathrm{~h}$ following a malaria paroxysm [7], while hyperlactataemia can persist for variable periods [3].

Severe malaria has been associated, in multiple studies, with parasites expressing particular members of the var virulence gene family [8-14]. This is a large family of $\sim 60$ highly variable genes that all encode variants of the protein $P$. falciparum Erythrocyte Membrane Protein 1 (PfEMP1). PfEMP1 is a key virulence factor: it is exported to the surface of parasite-infected erythrocytes, where it mediates adhesion to host cell receptors found on the endothelial lining of blood vessels. Thus, infected erythrocytes can adhere in the microvasculature and avoid splenic clearance (reviewed in [15]). In addition, the host immune system can recognise these 
PfEMP1 adhesins [16], however, the parasite has evolved to switch their expression regularly [17, 18], allowing immune evasion [19] and thus persistent and repeated infections [20, 21].

Vargenes are grouped into the groups ups A, B, C and E based on sequence similarities in their upstream region, as well as their chromosomal location and direction of transcription [22]. There appears to be a 'hierarchy' of switching, in which genes of the upsA group, encoding large and complex PfEMP1s that tend to correlate with severe disease [8-14], are expressed preferentially in immunologically naïve individuals [8]. There is some evidence that the upsB group also associates with severe malaria, whereas the upsC group usually does not $[10,11]$.

Vargenes are generally considered to be expressed in a mutually exclusive fashion [18], although this may not be strictly true in all strains $[23,24]$. Mutually exclusive expression means that at any one time, the majority of the family is silenced epigenetically via heterochromatin formation [25]. The Plasmodium sirtuins, PfSir2A and $\mathrm{B}$, contribute to this regulation of var expression by enforcing histone deacetylation and thus heterochromatic silencing. Disruption of either sirtuin gene in cultured 3D7 parasites leads to deregulated expression of many vargenes, with PfSir2A primarily controlling the groups ups $\mathrm{A}, \mathrm{C}$ and $\mathrm{E}$, while PfSir2B primarily controls the ups $\mathrm{B}$ group [26, 27].

These lines of evidence from in vitro cultured parasites informed a previous study of the correlation between sirtuin and vargene expression in in vivo human infections. qPCR was conducted on parasites directly isolated from Gambian patients with severe or mild malaria, revealing a correlation between elevated expression of PfSir2A and elevated expression of severe-disease-associated vargenes. This further correlated with patient phenotypes of fever and hyperlactataemia, leading to the hypothesis that these indictors of host stress might be detected by the parasite and translated, via sirtuin activity, into altered patterns of vargene expression [11]. A separate study subsequently conducted on East-African (Kenyan) rather than West-African (Gambian) isolates reproduced the correlation between fever, high PfSir2A expression, low pre-existing anti-PfEMP1 immunity, and - in this study - a generally elevated level of vartranscription rather than the elevation of any particular subgroup [28].

In this present study, conducted in vitro using recently-culture-adapted parasites, we endeavoured to establish whether the correlations detected in these field studies actually denote cause-and-effect relationships. Thus, indicating strategies evolved by the parasite to survive heat stress when a human host experiences malarial fevers. P. falciparum parasites were accordingly subjected to high temperature and high lactate levels in vitro, mimicking the high body temperature and hyperlactatemia that occur in severe malaria.

\section{Methods}

\section{Parasite lines and culture}

The reference strain of $P$. falciparum, 3D7 (obtained from MR4), and 3 Kenyan strains (obtained from the European Malaria Reagent Repository, ID9775, ID3518 and ID10668) were cultured in $0^{+}$erythrocytes obtained from the National Blood Transfusion Service (NBTS, Edgbaston, UK). Cultures were maintained at $4 \%$ haematocrit in Roswell Park Memorial Institute (RPMI) 1640 medium containing $25 \mu \mathrm{g} / \mathrm{ml}$ gentamicin sulphate, $0.2 \%$ sodium bicarbonate (Sigma, USA), 0.2\% Albumax II (Life technologies, New Zealand), and $4.3 \%$ pooled 
human serum. Standard continuous culturing was carried out for 3D7 as described [29], or for the Kenyan strains with more frequent media changes and at $1 \%$ haematocrit, as described [30]. Staging and parasitaemia were assessed from a thin blood smear stained with Hemacolor ${ }^{\circledR}$ Rapid (VWR, UK). Storage and disposal of blood were in accordance with the Human Tissue Authority (HTA) license held by Keele University.

\section{Cloning and expression of luciferase reporter gene}

The firefly luciferase gene (F/uc) was amplified from an existing expression cassette [31] using primers $\mathrm{P} 1$ and P2 (Additional file 1, Table S1), and ligated into the pLNSir2GFP plasmid [11] between the AfII and Avrl sites. Cloning was conducted in the PMC103 strain of E. coli (ATTC). The resulting plasmid, pLNSir2aproluc (Additional file 2, Figure S1A), was transfected into the 3D7 strain as previously described [32]. The full protocol is published in https://dx.doi.org/10.17504/protocols.io.btsxnnfn.

\section{Synchronization of parasites}

Double sorbitol synchronization was carried out as described [33], either $16 \mathrm{~h}$ apart (for the experiments with trophozoites) or $20 \mathrm{~h}$ apart (for the experiments with rings). A $20 \mathrm{~h}$ apart synchronization was required for the rings so as to ensure that synchrony is not lost as the parasites would have to invade new red blood cells and become rings again prior to the experiments.

\section{Stress treatment of parasites}

All field strains were stressed at $4 \%$ haematocrit. Trophozoites were subjected to high temperature $\left(40^{\circ} \mathrm{C}\right)$ and/or to $5 \mathrm{mM}$ sodium lactate for 2 or $6 \mathrm{~h}$. The rings were exposed to these stressors at $2 \pm 2$ hours post invasion (hpi) for $6 \mathrm{~h}$ only. This level of heat shock was chosen because temperatures above $40^{\circ} \mathrm{C}$ were previously shown to kill most mature forms of the asexual stage [34] and in our laboratory [unpublished data]. Control samples, cultured under normal culture conditions, were included for all time points. After the stress, the medium was completely changed and the cultures were used for transcriptional analysis: RNA was extracted immediately, or after $10 \mathrm{~h}$ recovery (in ring-stage experiments only). An aliquot of each culture was also diluted immediately after stress to parasitaemia of $0.5 \%$ (for trophozoites) or $0.1 \%$ (for rings) with $4 \%$ haematocrit in complete media, and this was then cultured for $48 \mathrm{~h}$ (for trophozoites) or $72 \mathrm{~h}$ (for rings) to determine survival rate. SYBR Green 1-based fluorescence assessment was conducted as described below. Survival was calculated using the equation: $(\mathrm{gt} / \mathrm{gc}) \times 100$, where $\mathrm{gt}=$ fluorescence of the test sample and $\mathrm{gc}=$ fluorescence of the control sample.

\section{SYBR Green 1-based fluorescence assessment}

Growth was assessed using the SYBR Green 1-based fluorescence method [35] by mixing $100 \mu$ l of the parasite cultures with $100 \mu \mathrm{l}$ of lysis buffer containing SYBR green at a 1:5000 dilution (lysis buffer $=20 \mathrm{mM}$ Tris pH 7.5, $5 \mathrm{mM}$ EDTA, $0.008 \% \mathrm{v} / \mathrm{v}$ saponin and $0.08 \% \mathrm{v} / \mathrm{v}$ Triton X-100) in the wells of a 96 -well black plate (CellStar, Greiner-bio-one, Germany) in the dark. The plates were then incubated for $1 \mathrm{~h}$ in the dark and the fluorescence intensity was measured using $490 \mathrm{~nm}$ excitation and $510-570 \mathrm{~nm}$ emission filter in a Glomax-Multi Detection System (Promega, UK). Raw fluorescence values were used to determine statistical significance.

\section{Luciferase reporter assay}


Stress experiments were conducted in the 3D7 PfSir2A-luc reporter line as above, using trophozoite stages only. A previously characterised luciferase reporter line, Dd2 Pfpcna-luc [31] was also included as a control in these experiments. Bioluminescence of the transgenic lines was measured immediately after stress using the improved Single-Step Lysis Protocol [36] in a Glomax-Multi Detection System (Promega, UK). Measurements were converted to relative luciferase activity as compared to the untreated transgenic line.

\section{Gene expression analysis}

Total RNA was extracted from each sample culture as described previously [37], but rather than adding Trizol to the iRBCs, Trizol was added directly to the parasite pellet after release from RBCs by saponin lysis at a concentration of $0.1 \%$, (using equal volume of a $0.2 \%$ solution of saponin to the pelleted blood). Free parasites were briefly washing with ice-cold sterile 1xPBS. RNA yield was quantified using a Nanospec 1000 (Thermoscientific, USA). Contaminating DNA was removed using the wipe out buffer in the QuantiTect® Reverse Transcription Kit (QIAGEN GmbH, Germany). cDNA was synthesized with this kit and the absence of contaminating genomic DNA was verified by PCR across the intron of the gene PF3D7_0424300, as described previously [38]. Relative gene expression of the sirtuins and vargenes was determined by qPCR in a StepOne Plus $^{\text {TM }}$ Real-time PCR machine (Thermo Fischer Scientific) using SensiFAST ${ }^{\text {тм }}$ SYBR (Bioline, UK), cDNA (diluted at most 1:20) and primers $(0.125 \mu \mathrm{M})$ in a $20 \mu$ reaction volume. Cycling conditions were $50^{\circ} \mathrm{C}$ for 2 min, initial denaturation at $95^{\circ} \mathrm{C}$ for $3 \mathrm{~min}$, followed by 40 cycles of denaturation at $95^{\circ} \mathrm{C}$ for $15 \mathrm{~s}$, annealing at $54^{\circ} \mathrm{C}$ for 40 $\mathrm{s}$ and elongation at $60^{\circ} \mathrm{C}$ for $1 \mathrm{~min}$. A melt-curve step was included to verify the specificity of the reactions. Reference genes used as controls were PF3D7_0717700 (serine tRNA-ligase), PF3D7_1444800 (FBP aldolase) and PF3D7_1246200 (actin). In ring-stage samples, the reference genes PF3D7_0501300 (SBP1) and PF3D7_1370300 (MAHRP1) were also measured as previously described [11] to confirm that parasites were consistently ring-stage. Data analysed with the inclusion of these reference genes are in Additional file 3. Primers to the target genes PfSir2A, PfSir2B [11], the major var gene groups [10], and the conserved acidic terminal segment (ATS) of all vargenes [11] were used as published. Primers to PfHsp70 (P3 and P4) and MAHRP1 (P5 and P6) were designed using Snapgene software, their specificity was validated and minimal formation of primer-dimers was confirmed. All primers were manufactured and HPSF®-purified by Eurofins mwg®. Primer sequences are in Additional file 1 (Tables S2 and S3).

The relative copy number (RCN) of each target gene in each sample was calculated relative to the average of three housekeeping genes. RCN was calculated from $2^{-\Delta C t}$. $\Delta \mathrm{Ct}$ is the difference between the $\mathrm{Ct}$ of a target gene and the average $\mathrm{Ct}$ of three housekeeping genes, as shown in Additional file 3 alongside all raw qPCR data. Log10 of the mean RCN is represented in all graphs, and the RCN for each biological replicate experiment was used to determine statistical significance. Mean fold change in expression was calculated from the difference in the means of the control and stressed groups by determining the inverse of the antilog of this mean difference.

\section{Statistical analysis}

Experiments with the laboratory strain, 3D7, were done in independent biological triplicates (independent here means that a new culture of the same parasite strain was used to set up the same stress experiments on a different day), each measured by qPCR in technical triplicate (technical means that the same culture of a parasite line was analysed three times in different wells after a single stress experiment), thus yielding a total 
of 3 independent RCN values. Experiments with the three field strains were done in independent biological duplicates, also assessed by qPCR in technical triplicate, thus yielding 2 independent RCN values. Statistical analysis was conducted with Minitab 19 for Windows. A General Linear Model was performed with log10 RCN as a response. Dichotomous categorical predictors of time, (2hrs or $6 \mathrm{hrs} / 6 \mathrm{hrs}$ or $16 \mathrm{hrs}$ ) temperature ( $37^{\circ}$ or $40^{\circ} \mathrm{C}$ ) and treatments (LAC 5mM or none). The log10 RCN showed no evidence of heteroscedasticity using Levene's test. Anderson Darling detected some residuals were non-normally distributed, the GLM was assumed to be robust to this as $\mathrm{n}$ was at least 32. Multiple comparisons were done using Turkey's pairwise comparisons across the categorical predictors.

\section{Results}

\section{Heat shock adversely affects parasite survival whereas lactate exposure does not}

In order to choose appropriate parameters for exposing parasites to either heat shock or elevated lactate, we first measured parasite survival following such exposures, both at the ring stage and at the trophozoite stage. Trophozoites are known to be more sensitive to heat shock than rings [39], and although comparable stagespecific data are not published for lactate sensitivity, the trophozoite is also the most metabolically active stage, at which lactate production is highest. Cultures were treated at either $2 \pm 2 \mathrm{hpi}$, or at $28 \pm 4$ hpi (primarily young rings and young trophozoites respectively). Exposure to stress was for $2 \mathrm{~h}$ or $6 \mathrm{~h}$ and consisted of heat shock at $40^{\circ} \mathrm{C}$ or $5 \mathrm{mM}$ added lactate. These were chosen to mimic, respectively, common levels of fever in the human host and the WHO threshold for hyperlactataemia that defines severe malaria [2]. Survival was measured $48 \mathrm{~h}$ after treatment of the trophozoites or $72 \mathrm{~h}$ after treatment of the rings, thus allowing reinvaded rings to develop into trophozoites, when the DNA content can parallel parasite numbers. Four parasite strains were used: the reference strain 3D7 and three recently laboratory-adapted strains derived from Kenyan malaria patients.

In trophozoites, heat shock resulted in 0-20\% death following a $2 \mathrm{~h}$ exposure and $20-40 \%$ death following a $6 \mathrm{~h}$ exposure (Fig. 1A). The extent of heat-shock-induced death appeared strain-dependent, with one strain (ID9775) appearing more sensitive. This field strain (ID9775) grew most rapidly and robustly in normal culture conditions. By contrast to heat shock, lactate exposure did not appear to have an adverse effect on parasite survival (Fig.1A) and when both stressors were applied together, results were very similar to those seen after heat shock alone (Fig. 1A).

When heat shock was applied to ring-stage parasites, survival after $72 \mathrm{~h}$ was more variable between strains than it had been at the trophozoite stage (Fig. 1 B). Kenyan strain ID3518 was almost completely insensitive, whereas rings of strains ID 9775 and ID 10668 were affected (27\% and $38 \%$ death, respectively, i.e. almost as severely affected as their trophozoites). Lactate exposure for $6 \mathrm{~h}$ at the ring stage again had little effect on parasite survival (Fig. 1 B).

\section{Heat shock modulates the expression of PfSir2B in P. falciparum trophozoites}


Having established heat shock conditions that caused only a moderate amount of parasite death in both trophozoites and rings, we measured the expression of sirtuin genes immediately after heat shock, as well as the expression of the gene encoding heat shock protein $70(h s p 70)$ as a positive control. These experiments were conducted first on trophozoites: the stage that was previously reported to upregulate PfSir2A expression after heat shock [34]. Across the strains, $h s p 70$ expression was indeed upregulated (Fig. 2A) by an average of $3-5$ folds (Table 1 ) in response to heat shock but not to lactate exposure, as expected.

PfSir2A appeared to be unaffected by heat shock or lactate treatment (Fig. 2B, Table 1). PfSir2B expression was increased after $2 \mathrm{~h}$ of heat shock but not after $6 \mathrm{~h}$ (Fig. 2C) with mean fold changes ranging from 1.5 - 2 folds (Table 1). This response was again heat-shock-specific because lactate versus no lactate was not significantly different, thus suggesting that heat shock was the main factor modulating the transcription of PfSir2B.

Table 1: Mean (95\% CI) fold changes in the expression of hsp70, Sir2A and Sir2B in trophozoites after a $2 \mathrm{~h}$ or $6 \mathrm{~h}$ exposure to $5 \mathrm{mM}$ Lactate or $40^{\circ} \mathrm{C}$ heat shock, alone or in combination.

\begin{tabular}{|c|c|c|c|}
\hline Gene/Time of expo & puræatate $5 \mathrm{mM}$ & $40^{\circ} \mathrm{C}$ & $40^{\circ} \mathrm{C}+$ Lactate $5 \mathrm{n}$ \\
\hline$H s p 702 \mathrm{~h}$ & 1.39 (0.49 to 3 & 8992 (1.73 to 14 & .3069 (1.06 to $12 . \$ 8$ \\
\hline Hsp70 6h & $1.06(0.57$ to 1 & $9990(2.06$ to 10 & $.8242(1.20$ to $9.7 \phi)$ \\
\hline $\operatorname{Sir} 2 A 2 \mathrm{~h}$ & 1.11 (0.43 to 2 & 8737 (0.57 to 3. & (6).90 (0.64 to 5.64$)$ \\
\hline $\operatorname{Sir} 2 A 6 \mathrm{~h}$ & $1.06(0.42$ to 2 & .7321 (0.52 to $2 . \oint$ & $\$ \mathrm{z}) .23(0.53$ to $2.8 \phi)$ \\
\hline $\operatorname{Sir} 2 B 2 \mathrm{~h}$ & 1.28 (0.59 to 2 & .7688 (1.11 to 3. & (a).45 (0.76 to 2.77) \\
\hline $\operatorname{Sir} 2 B 6 \mathrm{~h}$ & 1.07 (0.46 to 2 & 4998 (0.86 to 4. & \$4).48 (0.49 to 4.5 \\
\hline
\end{tabular}

Since there was no change in Sir2A expression after heat shock, we designed a second independent approach to measure this response. A luciferase reporter gene was cloned under the presumptive Sir2A promoter $(\sim 1.7 \mathrm{~kb}$ of the gene's upstream sequence) and the reporter gene was transfected into 3D7 parasites, where it was shown to follow an expression profile similar to that of the endogenous Sir2a gene across the intraerythrocytic cycle [40](Additional file 2, Figure S1B). Unfortunately, although this system may be useful in other applications, it proved unsuitable for heat shock experiments because the luciferase was severely destabilised at $40^{\circ} \mathrm{C}$ : activity dropped by $\sim 80 \%$ after a $2 \mathrm{~h}$ heat shock, irrespective of the promoter driving luciferase expression (Additional file 2, Figure S1C), thus obscuring any promoter-mediated regulation at the transcriptional level. 


\section{Pilot study on the alteration of sirtuins and var genes in P. falciparum ring stages after exposure to heat shock and lactate}

Figure 2 shows that exposure to heat shock modulates the expression of PfSir2B, in trophozoite-stage parasites. We therefore proceeded to investigate the same responses in ring-stage parasites, i.e. the stage at which vargenes are also expressed. Sirtuin and vargene expression were measured immediately after the rings had been exposed to heat shock, elevated lactate, or both stressors combined for $6 \mathrm{~h}$, i.e. expression was measured at $8 \mathrm{hpi}$. The same genes were also measured at $16 \mathrm{~h}$ (i.e. $10 \mathrm{~h}$ after the stressors were removed), at $18 \mathrm{hpi} \mathrm{-} \mathrm{around} \mathrm{the} \mathrm{time} \mathrm{of} \mathrm{maximum} \mathrm{expression} \mathrm{for} \mathrm{active} \mathrm{vargene(s)} \mathrm{[41].} \mathrm{Kenyan} \mathrm{field} \mathrm{strains} \mathrm{(ID9775} \mathrm{and}$ ID3518) were selected for these experiments and, since var gene families are hyper-diverse, var expression was measured using general primer sets that were previously developed to detect conserved regions within each ups-group of vargenes [10]. These same primers were used in the study of Gambian field strains which originally reported the association between vargene expression, sirtuin expression, patient fever and hyperlactataemia [11].

Preliminary findings show that on exposure of ring-stage parasites to heat shock, $h s p 70$ was upregulated (Fig. 3A) and Sir2A (Fig. 3B) trended upwards both after stress and $10 \mathrm{~h}$ of recovery at $37^{\circ} \mathrm{C}(16 \mathrm{~h}$ after the onset of heat shock), while Sir $2 B$ (Fig. 3C) trended downwards only after stress. These changes in $\operatorname{Sir} 2 A$ and $\operatorname{Sir} 2 B$ are not statistically significant.

The pattern of expression of vargenes was nondescript (Fig. 4A-I) but may be clearer if more samples are studied. However, the vargenes belonging to all the groups are upregulated after the $10 \mathrm{~h}$ of no stress ( $\mathrm{p}$ values are not shown for the time categorical factor). This most likely means that vargenes are increasingly expressed with time.

\section{Discussion}

This is the first study to use recently laboratory-adapted field strains, rather than just the established laboratory parasite 3D7, to examine links between $P$. falciparum sirtuin expression and elevated temperature, in vitro. The data presented here suggests this link is more likely between $P f S i r 2 B$ and fever temperatures, however more data is needed to confirm this.

High body temperature and high blood lactate were previously shown to be associated with upregulated sirtuin and var expression in Gambian field isolates of $P$. falciparum causing severe disease [11]. In a separate study, fever alone was associated with increased expression of PfSir2A and vargenes in Kenyan field isolates [28]. However, cause-and-effect relationships were not established in these studies. We have shown that $P f S i r 2 B$ can be increased in the trophozoites in response to heat shock, but the increase was not more than 2 folds on average. In addition, there was variability between the 3D7 biological replicates (Fig. 2A, first biological replicate showed a slight decrease). There is also a possibility that ring stages may respond to heat shock with a transient downregulation of $P f \operatorname{Sir} 2 B$ and an upregulation of $P f S i r 2 A$, but more biological replicate experiments are needed to establish this. It is possible that other factors that occur in in vivo during malaria may act in concert with heat shock to increase the expression of both sirtuins. 
In general, the changes in PfSir2B expression seen in both previous and present studies were quite modest, and a significant change in the level of a transcript does not necessarily indicate a biologically relevant change. Possible changes in sirtuin expression may correlate with increased expression of vargenes, as has been shown previously with the published findings from direct patient isolates $[11,28]$. Sir2A and vargenes have been shown to be increased in in vitro heat-shocked 3D7 parasites [34]. In this study, heat shock was applied for a shorter time ( $2 \mathrm{~h}$ vs $6 \mathrm{~h}$ here), and thus we may have missed the time when the 'stress' would have most likely led to an increased expression of vargenes. However, since vargenes appear to be increased with time [41], this may be unlikely. In addition, it is important to note that an asynchronous parasite population was used in this previously published study [34], thus making the observations in this laboratory study akin to that of the field studies where the ring stages of all ages can be found in circulation. In this study, we have tried to streamline expression profiles by using a highly synchronous parasite population.

Finally, during the preparation of this manuscript, a third study was published examining var and PfSir2A expression in parasite-positive individuals in Mozambique [42]. Unlike the Gambian and Kenyan patients, these subjects were identified via a community survey, with none being severely ill or attending a clinic, although some did have an actual or reportedly-recent fever. PfSir2A transcription was actually lower in the febrile group than in the afebrile group - perhaps suggesting that our hypothesis concerning PfSir2A levels may only be significant in cases of more severe and symptomatic disease.

By contrast with the results discussed above concerning the relationship between fever and virulence gene expression, we did not detect any comparable response to elevated lactate levels. This suggests that although hyperlactataemia was clearly identified in our original field study as a correlate of sirtuin upregulation [11], the correlation is probably not causative. Alternatively, the level of lactate used here may not have been high enough to see an effect - $5 \mathrm{mM}$ is at, not above, the clinical threshold. However, only $26 \%$ of the original patient cohort in the Gambian study [11] had lactate levels $>5 \mathrm{mM}$, suggesting that in vivo this is indeed relatively rare, and aberrantly high.

\section{Conclusion}

Overall, the data presented here suggest that observations made in the West-African field study of patients with severe versus mild malaria [11] do reflect a causative relationship between fever in the human host and expression of $P f S i r 2 B$ in the trophozoite stages, but not between fever and the sirtuins or varvirulence genes in the ring stages. The modest increase of PfSir2B only in the trophozoites and no change in sirtuin or vargenes in the rings indicates a challenge in recapitulating in vivo observations using an in vitro approach. Furthermore, the ability of sirtuin activity to bring about a change in vartranscription directly can be investigated with experiments, such as vargene ChIP for modified histones, or generation of sirtuin knockouts, which would be challenging in newly-cultured field strains. Also, the interplay between PfSir2A and PfSir2B remains uncharacterised and is probably complex.

\section{List Of Abbreviations}

DNA - Deoxyribonucleic acid

EDTA - Ethylenediaminetetraacetic acid Hsp70 - Heat shock protein-70

Page 9/18 
MR4 - The Malaria Research and Reference Reagent Resource Centre

MSF - Malaria SYBR Green 1-based fluorescence assay

PfEMP1 - P. falciparum Erythrocyte Membrane Protein 1

PBS - Phosphate-buffered saline

PfSir2A - Plasmodium falciparum silent information regulator 2A

PfSir2B - Plasmodium falciparum silent information regulator 2B

RBC - Red blood cell

RNA - Ribonucleic acid

qPCR - quantitative polymerase chain reaction

WHO - World health organization

\section{Declarations}

\section{Ethics approval and consent to participate}

Not applicable. All parasite strains were obtained from registered repositories, rather than directly from human patients. De-identified human erythrocytes in which $P$. falciparum strains were cultured was obtained from the National Blood Service. The use of blood is regulated under the Human Tissues Act 2004 and Keele University is an approved user of the National Blood Service.

\section{Consent for publication}

Not applicable

\section{Availability of data and material}

All data generated or analysed during this study are included in this published article.

\section{Competing interests}

The authors declare that they have no competing interests.

\section{Funding}

This work was partially funded by the tertiary Education Trust Fund (TETfund) Nigeria. The funders had no role in the study design, data collection and analysis, decision to publish, or preparation of the manuscript.

\section{Authors' contributions}


LOA conducted experiments, designed some aspects of the study, analysed data with the assistance of DRH and drafted the manuscript. PDH assisted in the design of the luciferase experiments, provided the control luciferase-expressing strain and reviewed the manuscript. SJC supervised the study. All authors read and approved the final manuscript.

\section{Acknowledgements}

We are grateful to Dr. Catherine J Merrick for designing the study and majorly supervising the study and Dr. Imran Ullah for help in developing the heat shock experiments.

\section{References}

1. WHO: World Malaria Report 2020. 2020.

2. WHO: Severe Malaria. Tropical Medicine and International Health 2014, 19:7-131.

3. Krishna S, Waller DW, ter Kuile F, Kwiatkowski D, Crawley J, Craddock CF, Nosten F, Chapman D, Brewster D, Holloway PA, et al.: Lactic acidosis and hypoglycaemia in children with severe malaria: pathophysiological and prognostic significance. Trans R Soc Trop Med Hyg 1994, 88:67-73.

4. Mockenhaupt FP, Ehrhardt S, Burkhardt J, Bosomtwe SY, Laryea S, Anemana SD, Otchwemah RN, Cramer JP, Dietz E, Gellert S, Bienzle U: Manifestation and outcome of severe malaria in children in northern Ghana. Am J Trop Med Hyg 2004, 71:167-172.

5. Agbenyega T, Angus BJ, Bedu-Addo G, Baffoe-Bonnie B, Guyton T, Stacpoole PW, Krishna S: Glucose and lactate kinetics in children with severe malaria. J Clin Endocrinol Metab 2000, 85:1569-1576.

6. Casals-Pascual C, Kai O, Lowe B, English M, Williams TN, Maitland K, Newton CR, Peshu N, Roberts DJ: Lactate levels in severe malarial anaemia are associated with haemozoin-containing neutrophils and low levels of IL-12. Malar J 2006, 5:101.

7. Bartoloni A, Zammarchi L: Clinical aspects of uncomplicated and severe malaria. Mediterr J Hematol Infect Dis 2012, 4:e2012026.

8. Jensen AT, Magistrado P, Sharp S, Joergensen L, Lavstsen T, Chiucchiuini A, Salanti A, Vestergaard LS, Lusingu JP, Hermsen R, et al: Plasmodium falciparum associated with severe childhood malaria preferentially expresses PfEMP1 encoded by group A var genes. J Exp Med 2004, 199:1179-1190.

9. Kyriacou HM, Stone GN, Challis RJ, Raza A, Lyke KE, Thera MA, Kone AK, Doumbo OK, Plowe CV, Rowe JA: Mol Biochem Parasitol 2006, 150:211-218.

10. Rottmann M, Lavstsen T, Mugasa JP, Kaestli M, Jensen AT, Muller D, Theander T, Beck HP: Differential expression of var gene groups is associated with morbidity caused by Plasmodium falciparum infection in Tanzanian children. Infect Immun 2006, 74:3904-3911.

11. Merrick CJ, Huttenhower C, Buckee C, Amambua-Ngwa A, Gomez-Escobar N, Walther M, Conway DJ, Duraisingh MT: Epigenetic dysregulation of virulence gene expression in severe Plasmodium falciparum malaria. J Infect Dis 2012, 205:1593-1600.

12. Abdi Al, Fegan G, Muthui M, Kiragu E, Musyoki JN, Opiyo M, Marsh K, Warimwe GM, Bull PC: Plasmodium falciparum antigenic variation: relationships between widespread endothelial activation, parasite PfEMP1 expression and severe malaria. BMC Infect Dis 2014, 14:170. 
13. Storm J, Jespersen JS, Seydel KB, Szestak T, Mbewe M, Chisala NV, Phula P, Wang CW, Taylor TE, Moxon $\mathrm{CA}$, et al: Cerebral malaria is associated with differential cytoadherence to brain endothelial cells. $E M B O$ Mol Med 2019, 11.

14. Claessens A, Adams Y, Ghumra A, Lindergard G, Buchan CC, Andisi C, Bull PC, Mok S, Gupta AP, Wang CW, et al: A subset of group A-like var genes encodes the malaria parasite ligands for binding to human brain endothelial cells. Proc Natl Acad Sci U S A 2012, 109:E1772-1781.

15. Pasternak ND, Dzikowski R: PfEMP1: an antigen that plays a key role in the pathogenicity and immune evasion of the malaria parasite Plasmodium falciparum. Int J Biochem Cell Biol 2009, 41:1463-1466.

16. Newbold Cl, Pinches R, Roberts DJ, Marsh K: Plasmodium falciparum: the human agglutinating antibody response to the infected red cell surface is predominantly variant specific. Exp Parasitol 1992, 75:281-292.

17. Roberts DJ, Craig AG, Berendt AR, Pinches R, Nash G, Marsh K, Newbold Cl: Rapid switching to multiple antigenic and adhesive phenotypes in malaria. Nature 1992, 357:689-692.

18. Scherf A, Hernandez-Rivas R, Buffet P, Bottius E, Benatar C, Pouvelle B, Gysin J, Lanzer M: Antigenic variation in malaria: in situ switching, relaxed and mutually exclusive transcription of var genes during intra-erythrocytic development in Plasmodium falciparum. Embo J 1998, 17:5418-5426.

19. Abdi Al, Hodgson SH, Muthui MK, Kivisi CA, Kamuyu G, Kimani D, Hoffman SL, Juma E, Ogutu B, Draper SJ, et al: Plasmodium falciparum malaria parasite var gene expression is modified by host antibodies: longitudinal evidence from controlled infections of Kenyan adults with varying natural exposure. BMC Infect Dis 2017, 17:585.

20. Franks S, Koram KA, Wagner GE, Tetteh K, McGuinness D, Wheeler JG, Nkrumah F, Ranford-Cartwright L, Riley EM: Frequent and persistent, asymptomatic Plasmodium falciparum infections in African infants, characterized by multilocus genotyping. J Infect Dis 2001, 183:796-804.

21. Ashley EA, White NJ: The duration of Plasmodium falciparum infections. Malar J 2014, 13:500.

22. Lavstsen T, Salanti A, Jensen AT, Arnot DE, Theander TG: Sub-grouping of Plasmodium falciparum 3D7 var genes based on sequence analysis of coding and non-coding regions. Malar J 2003, 2:27.

23. Merrick CJ, Jiang RH, Skillman KM, Samarakoon U, Moore RM, Dzikowski R, Ferdig MT, Duraisingh MT: Functional analysis of sirtuin genes in multiple Plasmodium falciparum strains. PLoS One 2015, 10:e0118865.

24. Joergensen L, Bengtsson DC, Bengtsson A, Ronander E, Berger SS, Turner L, Dalgaard MB, Cham GK, Victor ME, Lavstsen T, et al: Surface co-expression of two different PfEMP1 antigens on single plasmodium falciparum-infected erythrocytes facilitates binding to ICAM1 and PECAM1. PLoS Pathog, 6:e1001083.

25. Freitas-Junior LH, Hernandez-Rivas R, Ralph SA, Montiel-Condado D, Ruvalcaba-Salazar OK, Rojas-Meza AP, Mancio-Silva L, Leal-Silvestre RJ, Gontijo AM, Shorte S, Scherf A: Telomeric heterochromatin propagation and histone acetylation control mutually exclusive expression of antigenic variation genes in malaria parasites. Cell 2005, 121:25-36.

26. Duraisingh MT, Voss TS, Marty AJ, Duffy MF, Good RT, Thompson JK, Freitas-Junior LH, Scherf A, Crabb BS, Cowman AF: Heterochromatin silencing and locus repositioning linked to regulation of virulence genes in Plasmodium falciparum. Cell 2005, 121:13-24.

27. Tonkin CJ, Carret CK, Duraisingh MT, Voss TS, Ralph SA, Hommel M, Duffy MF, Silva LM, Scherf A, Ivens A, et al: Sir2 paralogues cooperate to regulate virulence genes and antigenic variation in Plasmodium 
falciparum. PLoS Biol 2009, 7:e84.

28. Abdi Al, Warimwe GM, Muthui MK, Kivisi CA, Kiragu EW, Fegan GW, Bull PC: Global selection of Plasmodium falciparum virulence antigen expression by host antibodies. Sci Rep 2016, 6:19882.

29. Ménard RE: Malaria: Methods and Protocols.2013.

30. Radfar A, Mendez D, Moneriz C, Linares M, Marin-Garcia P, Puyet A, Diez A, Bautista JM: Synchronous culture of Plasmodium falciparum at high parasitemia levels. Nat Protoc 2009, 4:1899-1915.

31. Wong EH, Hasenkamp S, Horrocks P: Analysis of the molecular mechanisms governing the stage-specific expression of a prototypical housekeeping gene during intraerythrocytic development of P. falciparum. $J$ Mol Biol 2011, 408:205-221.

32. Deitsch K, Driskill C, Wellems T: Transformation of malaria parasites by the spontaneous uptake and expression of DNA from human erythrocytes. Nucleic Acids Res 2001, 29:850-853.

33. Lambros C, Vanderberg JP: Synchronization of Plasmodium falciparum erythrocytic stages in culture. $J$ Parasitol 1979, 65:418-420.

34. Oakley MS, Kumar S, Anantharaman V, Zheng H, Mahajan B, Haynes JD, Moch JK, Fairhurst R, McCutchan TF, Aravind L: Molecular factors and biochemical pathways induced by febrile temperature in intraerythrocytic Plasmodium falciparum parasites. Infect Immun 2007, 75:2012-2025.

35. Smilkstein M, Sriwilaijaroen N, Kelly JX, Wilairat P, Riscoe M: Simple and inexpensive fluorescence-based technique for high-throughput antimalarial drug screening. Antimicrob Agents Chemother 2004, 48:18031806.

36. Hasenkamp S, Wong EH, Horrocks P: An improved single-step lysis protocol to measure luciferase bioluminescence in Plasmodium falciparum. Malar J 2012, 11:42.

37. Taylor HM, Kyes SA, Harris D, Kriek N, Newbold Cl: A study of var gene transcription in vitro using universal var gene primers. Mol Biochem Parasitol 2000, 105:13-23.

38. Merrick CJ, Dzikowski R, Imamura H, Chuang J, Deitsch K, Duraisingh MT: The effect of Plasmodium falciparum Sir2a histone deacetylase on clonal and longitudinal variation in expression of the var family of virulence genes. Int J Parasitol 2010, 40:35-43.

39. Kwiatkowski D: Febrile temperatures can synchronize the growth of Plasmodium falciparum in vitro. $J$ Exp Med 1989, 169:357-361.

40. Otto TD, Wilinski D, Assefa S, Keane TM, Sarry LR, Bohme U, Lemieux J, Barrell B, Pain A, Berriman M, et al: New insights into the blood-stage transcriptome of Plasmodium falciparum using RNA-Seq. Mol Microbiol 2010, 76:12-24.

41. Dahlback M, Lavstsen T, Salanti A, Hviid L, Arnot DE, Theander TG, Nielsen MA: Changes in var gene mRNA levels during erythrocytic development in two phenotypically distinct Plasmodium falciparum parasites. Malar J 2007, 6:78.

42. Gupta H, Galatas B, Matambisso G, Nhamussua L, Cistero P, Bassat Q, Casellas A, Macete E, Aponte JJ, Sacoor C, et al: Differential expression of var subgroups and PfSir2a genes in afebrile Plasmodium falciparum malaria: a matched case-control study. Malar J 2019, 18:326.

\section{Figures}



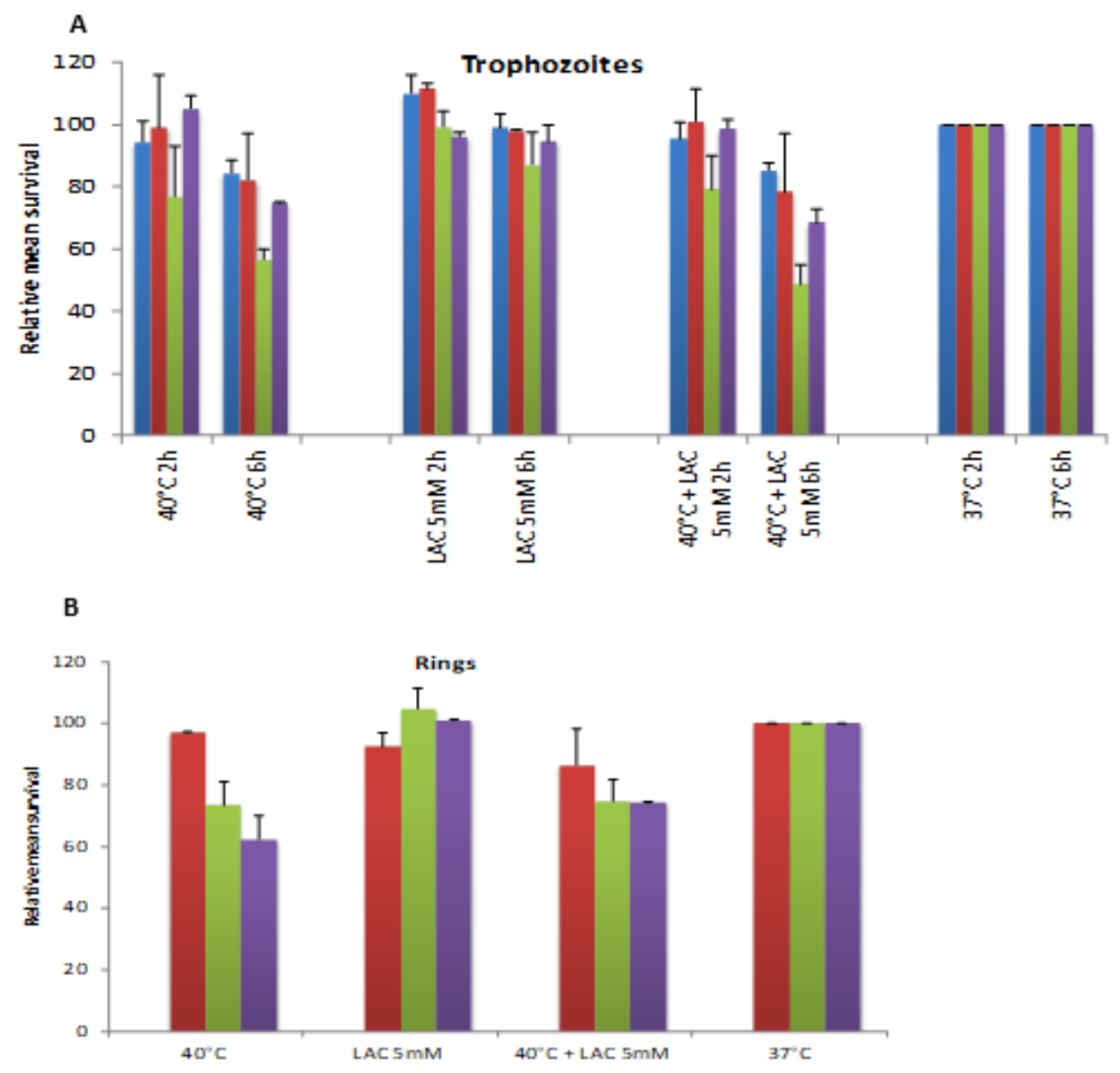

\section{Figure 1}

Post-stress survival of P. falciparum after exposure to lactate and heat shock. A. Parasite survival $48 \mathrm{~h}$ after stress treatment for $2 \mathrm{~h}$ or $6 \mathrm{~h}$ at the trophozoite stage, relative to growth of a control culture, measured via DNA content in a SYBR-Green-1 based assay. B. Parasite survival $72 \mathrm{~h}$ after stress treatment for $6 \mathrm{~h}$ at the ring stage, relative to growth of a control culture, measured via DNA content in a SYBR-Green-1 based assay. Blue bars, 3D7; red bars, ID3518; green bars, ID9775; purple bars, ID10668. Mean survival rates are from biological duplicates for the Kenyan strains, or triplicates for 3D7. Error bars represent standard error. 

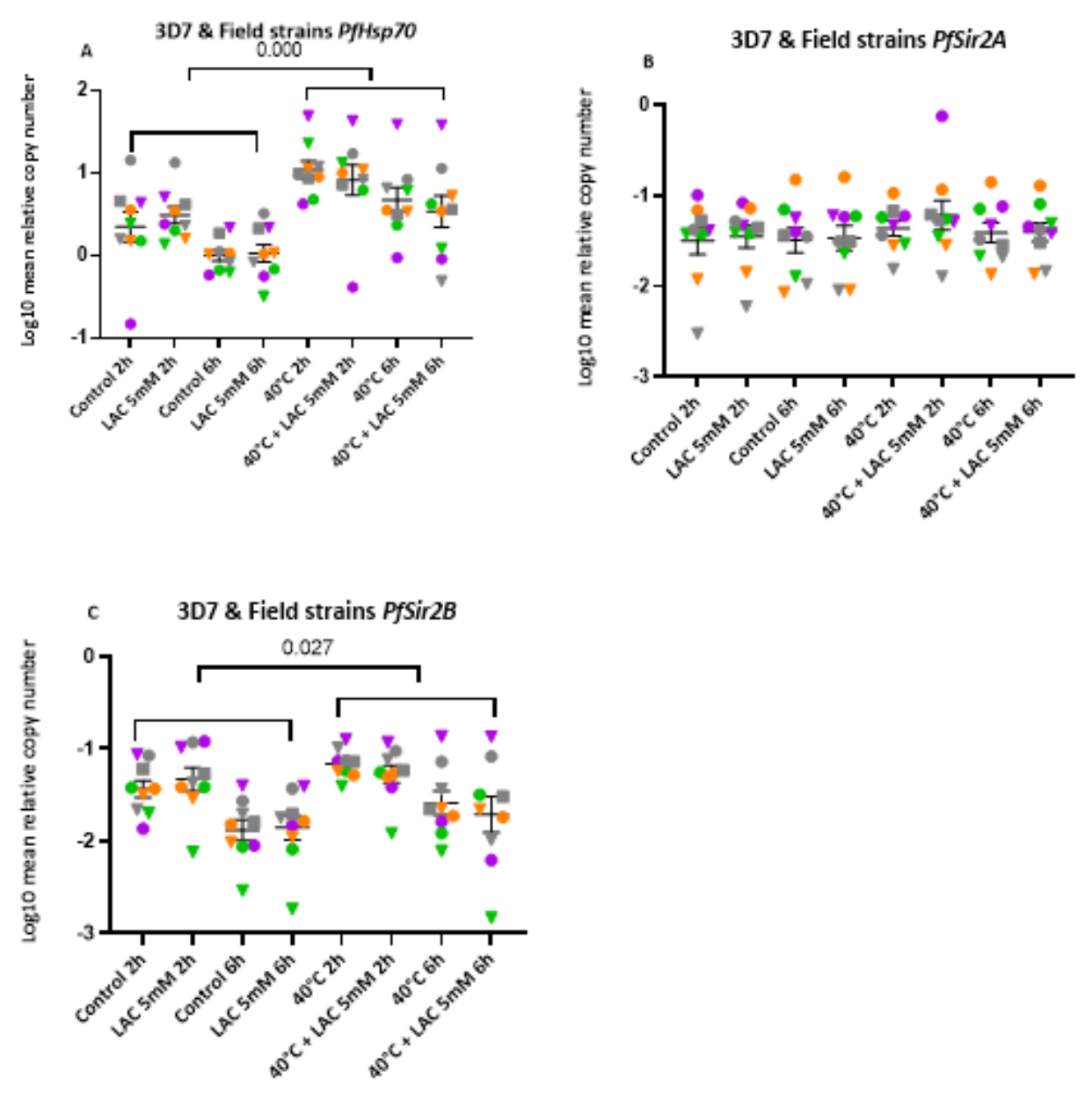

\section{Figure 2}

Increased expression of Hsp70 and PfSir2B in response to heat shock in trophozoites of P. falciparum. Log10 mean relative copy number of $\operatorname{Hsp} 70(A)$, Sir2A (B) and Sir2B (C) in parasites after stress treatments. Grey, purple, green and orange are data from strains 3D7, ID3518, ID9775 and ID10668, respectively. Circles, inverted triangles and squares are data from the first, second and third biological replicate experiments respectively. Error bars represent standard error mean. For Hsp70 and Sir2B, respectively, $\mathrm{p}=0.000$ and $0.027 \mathrm{for}$ the difference in the comparison of the temperature categorical factor $\left(40^{\circ} \mathrm{C}\right.$ (with or without lactate) vs $37^{\circ} \mathrm{C}$ (with or without lactate). 

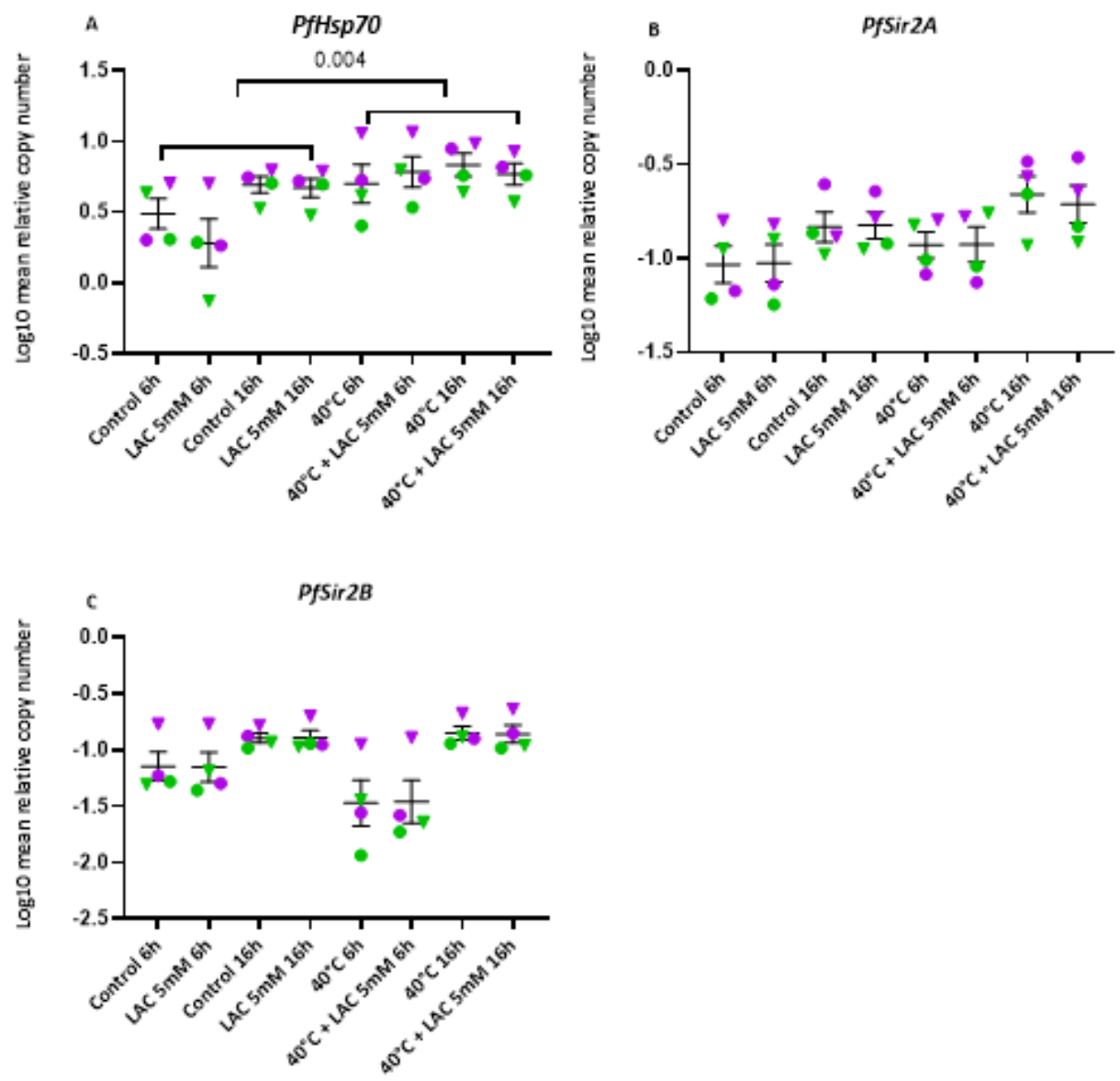

\section{Figure 3}

Sirtuin transcription pattern in ring-staged P. falciparum parasites after stress. Log10 mean relative copy number of Hsp70 (A), Sir2A (B) and Sir2B (C) in parasites after $6 \mathrm{~h}$ of stress treatments and after a further $10 \mathrm{~h}$ of no stress ('recovery', at $16 \mathrm{~h}$ from the time the stress was applied). Purple and green are data from strains ID3518 and ID9775, respectively. Circles and inverted triangles are data from the first and second biological replicate experiments respectively. Error bars represent standard error mean. For Hsp70, p 0.004 for the difference in the comparison of the temperature categorical factor $\left(40^{\circ} \mathrm{C}\right.$ (with or without lactate) vs $37^{\circ} \mathrm{C}$ (with or without lactate). 

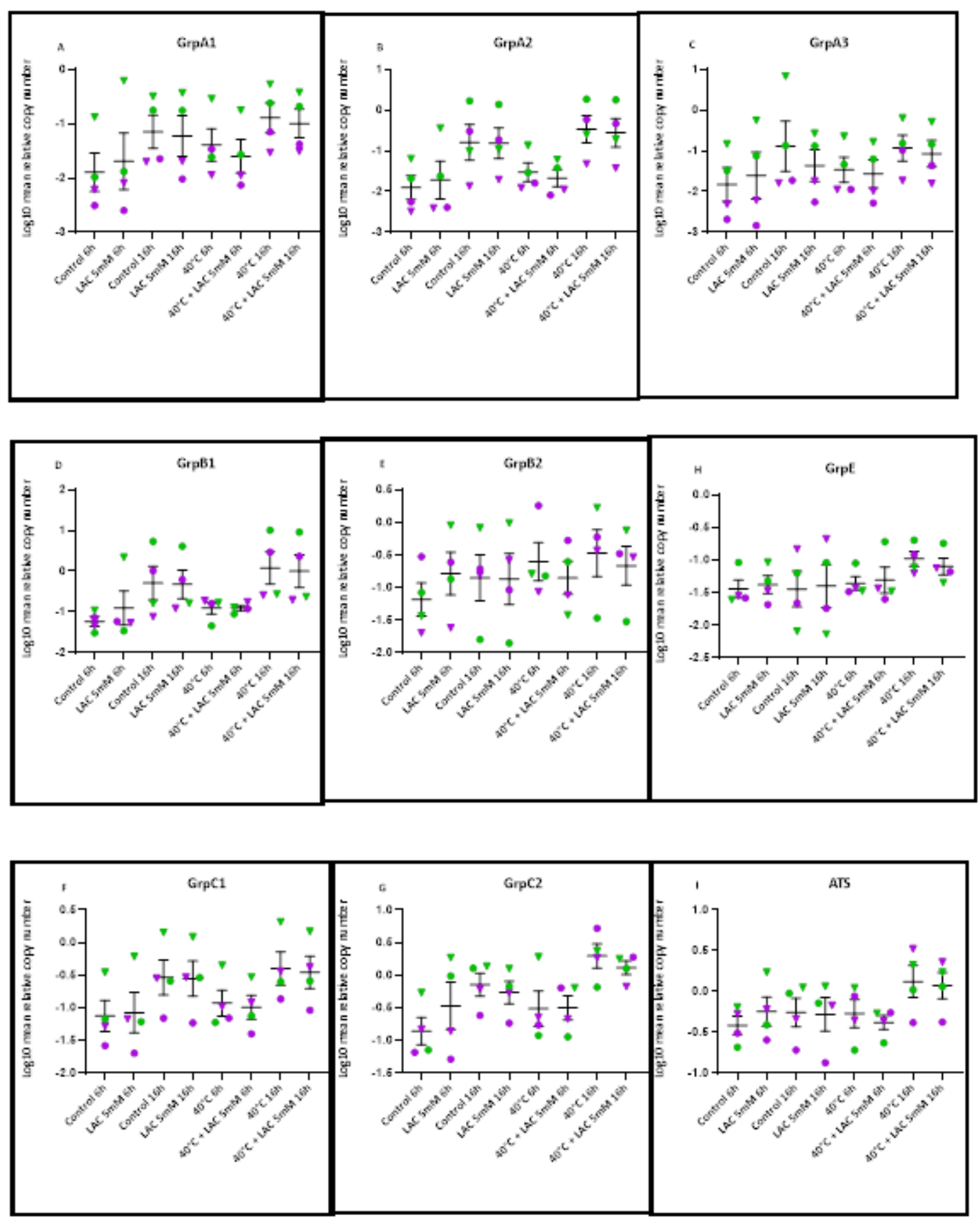

\section{Figure 4}

Var gene transcription in ring-staged P. falciparum parasites after stress. Log10 mean relative copy number of GrpA1 (A), GrpA2 (B) GrpA3 (C), GrpB1 (D), GrpB2 (E), GrpC1 (F), GrpC2 (G), GrpE (H) var genes and their ATS (I) in parasites after $6 \mathrm{~h}$ of stress treatments and after a further $10 \mathrm{~h}$ of no stress ('recovery', at $16 \mathrm{~h}$ from the time the stress was applied). Purple and green are data from strains ID3518 and ID9775, respectively. Circles and inverted triangles are data from the first and second biological replicate experiments respectively. Error bars represent standard error mean.

\section{Supplementary Files}


This is a list of supplementary files associated with this preprint. Click to download.

- Additionalfile1.docx

- Additionalfile2.pdf

- Additionalfile3qPCRrawdata.xlsx 